\title{
Study on accuracy of panorama and CBCT through length measurement of wisdom teeth
}

\author{
Cheonsoo Jeong, ${ }^{* * * *}$, Chongyeal Kim* \\ Department of Radiation Science \& Technology, Chonbuk University, Yedamdental Hospital ${ }^{* *}$ \\ 사랑니 길이 측정을 통한 파노라마와 $\mathrm{CBCT}$ 의 정확도 연구 \\ 정천수 ${ }^{* * * *}$, 김종일* \\ 전북대학교 방사선과학기술학과*, 예닮치과병원 ${ }^{* *}$
}

\begin{abstract}
Panorama of dental radiation generators can observe the wide anatomical structures of oral and maxillofacial areas but there can be distortion of lengths, angles, or shapes. CBCT can diagnose 3D images and get the ones whose errors by superposition and interference are remarkably smaller between anatomical structures. But the quality of the images by movement of subjects can be lowered as it takes long to diagnose them. And if there are impermeable radiation objects like metal in mouths, impermeable radiation lines can radially appear with the objects as center. This study tries to analyze accuracy of panorama and CBCT and get useful anatomical information in dental treatment by comparing the length of wisdom teeth which were measured by Panorama and $\mathrm{CBCT}$ with the teeth which were actually extracted and analyzing distortion of the teeth.

The test result could be found that Panorama is expanded by average $7.3 \%$ as the errors of Panorama and Digital Vernier Caliper range from $110.7 \%$ to $103.9 \%$. The length of wisdom teeth which were measured in $\mathrm{CBCT}$ and Digital Vernier Caliper could be found that the error range is 1.3\%. And the length of wisdom teeth which were measured in Panorama and Digital Vernier Caliper has found that the error range shows 7.3\%. So it could be found that the images of $\mathrm{CBCT}$ is about $6 \%$ more exact than those of Panorama.

It could be found that $\mathrm{CBCT}$ shows the more exact images than those of Panorama. But because the examination expenses of $\mathrm{CBCT}$ are higher than those of Panorama and exposure dose of $\mathrm{CBCT}$ is much more than that of Panorama, it is thought to find proper ways in examination.
\end{abstract}

Key Words : dental radiation, CBCT, panorama

\section{요약}

치과 방사선 발생장치 중 파노라마는 구강악안면의 넓은 해부학적 구조물을 관찰할 수 있으나, 길이나 각도, 형태의 왜곡이 일어날 수 있다. $\mathrm{CBCT}$ 는 3 차원적 영상진단을 할 수 있으며, 해부학적 구조물 사이의 중첩과 간섭에 의한 오차 가 현저히 적은 영상을 얻을 수가 있으나, 시간이 길어 피사체의 움직임에 의해 상의 질이 저하될 수 있고 구강 내에 금속 같은 방사선 불투과성 물체가 존재하면 그 물체를 중심으로 방사상으로 방사선 불투과성 선이 나타날 수 있다. 
본 연구에서는 파노라마와 $\mathrm{CBCT}$ 로 측정된 사랑니 길이와 실제 발치된 치아를 비교하여 치아의 왜곡을 분석함으로써 파노라마와 $\mathrm{CBCT}$ 의 정확도를 분석하고, 치과 치료시 해부학적으로 유용한 정보를 얻고자 한다.

실험결과 파노라마와 Digital Vernier Caliper의 오차는 크게는 $110.7 \%$, 작게는 $103.9 \%$ 로 평균적으로 파노라마가 평균 $7.3 \%$ 로 확대됨을 알 수 있었다. $\mathrm{CBCT}$ 와 Digital Vernier Caliper에서 측정된 사랑니의 길이는 오차범위 $1.3 \%$ 로 나타났고, 파노라마와 Digital Vernier Caliper에서 측정된 사랑니의 길이는 오차범위 $7.3 \%$ 를 나타냄으로써 $\mathrm{CBCT}$ 가 파노라마보다 약 $6 \%$ 정확한 영상을 나타냄을 알 수 있었다.

$\mathrm{CBCT}$ 가 파노라마보다 정확한 영상을 나타냄을 확인할 수 있었지만 $\mathrm{CBCT}$ 는 파노라마보다 검사비용이 비싸고 피폭 선량 또한 많아서 검사 시 적절한 방법을 찾아야 할 것으로 사료된다.

중심단어: 치과방사선, Cone beam형 전산화 단층촬영, 파노라마

\section{I. 서론}

치과 파노라마(panorama) 촬영은 구강악안면의 넓은 해부학적 구조물을 관찰할 수 있으며, 치아의 높이 및 주요 해부학적 구조물의 대략적인 위치 및 크기를 알 수 있다. 하지만 파노라마 촬영은 3 차원적인 입체 구 조물을 2 차원 평면으로 투영하는 것이므로 길이나 각 도, 형태의 왜곡현상이 발생하여 정량적인 평가 시 부 정확한 결과를 야기할 수 있다 ${ }^{[1,2]}$. 또 환자의 두부위치 에 따른 영상의 변화가 심하고 악골의 부위에 따라 $10 \sim 30 \%$ 까지 다양한 확대율을 나타내므로 상의 변형 과 확대를 예측하기 어려워 해부학적 구조물간의 실 제거리를 측정하기 어렵다. 또한 2차원 상을 제공하기 때문에 구조물의 중첩이 발생하고 골밀도 평가가 어 려우며 협설폭경과 해부학적 구조물의 위치를 정확하 게 평가할 수 없다는 단점이 있다 ${ }^{[3]}$.

최근 임상에 적용되고 있는 Cone Beam형 전산화단 층촬영기(이하 $\mathrm{CBCT})$ 는 기존의 $\mathrm{CT}$ 보다 상대적으로 낮은 선량이며, 3 차원적 영상진단을 할 수 있어 치과 병, 의원에 급속도로 보급되고 있다 ${ }^{[4,5]}$. CBCT는 2 차원 의 투영된 영상이 아니라, 입체적인 자료를 그대로 활 용할 수 있어 해부학적 구조물 사이의 중첩과 간섭에 의한 오차가 현저히 적은 영상을 얻을 수가 있다. 두 개안면부의 입체적인 영상을 구성할 수 있고 컴퓨터 의 조작을 통해 관찰이 용이하도록 원하는 위치로의 회전과 축의 조정이 가능하다. 그리고 상의 중복 없이 관심 있는 부분을 자세히 관찰할 수 있으며, 높은 해 상력을 가지므로 기존의 파노라마 영상이 조직 간에 $10 \%$ 정도의 밀도차가 있어야 구별이 가능한 것에 비 하여, 물리적 밀도 차이가 $1 \%$ 이하인 조직 간의 구별
이 가능하다. 컴퓨터의 재구성에 의하여 여러 가지 상 을 얻을 수 있으며, 3 차원적인 재구성이 가능하다. 하 지만 X선 조사 시간이 길어 피사체의 움직임에 의해 상의 질이 저하될 수 있고 구강 내에 금속 같은 방사 선 불투과성 물체가 존재하면 그 물체를 중심으로 방 사상으로 방사선 불투과성 선이 나타날 수 있다 ${ }^{[6-9]}$.

사랑니는 치근이 만곡되고, 치관이 파절되며, 치조 골의 유착이 될 수 있으므로, 파노라마와 $\mathrm{CBCT}$ 촬영 을 통해 정확한 위치를 확인하고 발치한다[10].

본 연구에서는 파노라마와 $\mathrm{CBCT}$ 로 측정된 사랑니 길이와 실제 발치된 치아를 비교하여 치아의 왜곡을 분석함으로써 파노라마와 $\mathrm{CBCT}$ 의 정확도를 분석하고, 치과 치료시 해부학적으로 유용한 정보를 얻고자 한 다.

\section{II. 연구대상 및 측정방법}

\section{1. 연구대상 및 장비}

2012년 3월부터 10월까지 사랑니 발치를 목적으로 파노라마와 $\mathrm{CBCT}$ 를 촬영한 환자 10 명을 대상으로 하 였다. 환자군은 영상에 불필요한 영향이 미치지 않게 보철 및 교정을 하지 않은 환자 위주로 선발하였다. 파노라마는 DP-90-P PAX-500 (Vatech, Korea), CBCT는 DCT-90-P IMPLAGRAPHY Dental CT system (Vatech, Korea)을 사용하였다.

\section{2. 실험 방법}

치아는 편의상 외부로 노출된 부분인 치관(crown), 치은에 감싸여 있는 목부분에 해당하는 지경(neck), 그 
리고 치조골에 단단하게 박혀 있는 부분인 치근(root) 으로 구분하며, 치아 전체는 법랑질(enamel), 상아질 (dentin), 치수(pulp), 백악질(cementum)으로 이루어져 있 다. 본 실험에서는 사랑니의 치관에서 치근까지 길이 측정을 하였다.

파노라마는 EasyDent Viewer V3.745 프로그램을 이 용하여 사랑니에 대한 길이 측정을 하였다. $\mathrm{CBCT}$ 는 촬영 후 바텍에서 제공하는 프로그램인 EZimplant Dental3D-Professional을 하였고, Sagittal, Coronal, Paraxial, Oblique plane을 실시간으로 Axial 영상의 Quality와 유사하게 재구성하는 기법인 Multi Planar Reformation(이하 MPR) 영상을 획득하고 교합평면에 대한 수직 절단면 영상(Cross-Sectional image)을 얻어 실험 자료로 사용하였다. 발치된 치아는 정확한 측정 을 위해 Digital Vernier Caliper로 측정하였다. 각 방법 에 따른 측정횟수를 최소 3 회를 기준으로 하여 평균값 을 구하였다.

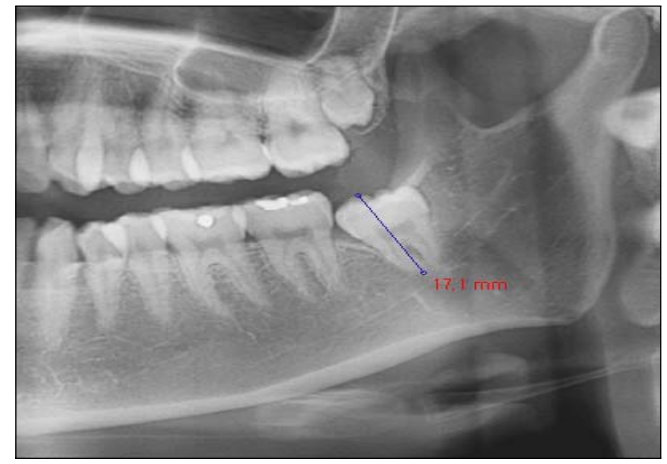

Fig 1. Wisdom tooth of panorama

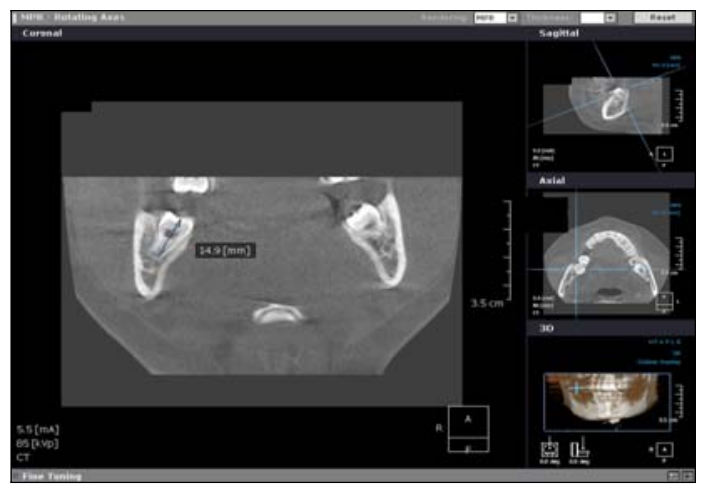

Fig 2. Wisdom tooth of $\mathrm{CBCT}$

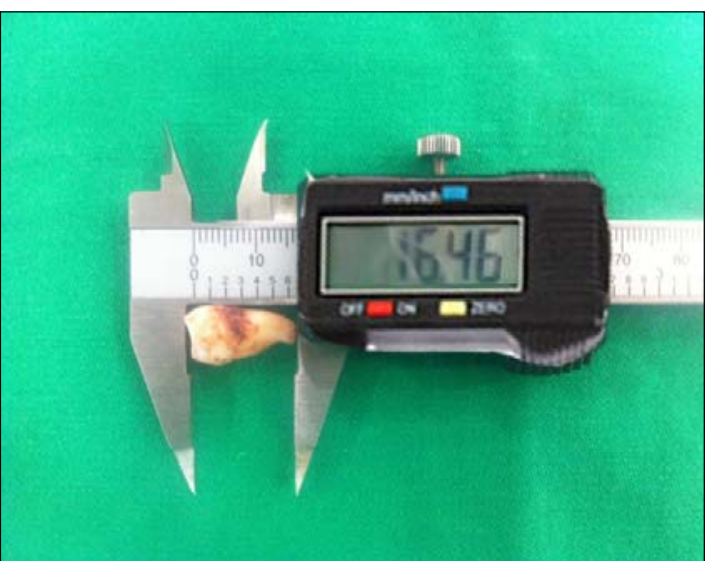

Fig 3. Digital Vernier Caliper

\section{III 연구 결과}

환자마다 사랑니의 길이가 차이가 있었지만, 발치 된 사랑니의 길이와 파노라마와 $\mathrm{CBCT}$ 에서 측정된 사 랑니의 길이를 비교했을 때 장비별로 큰 차이가 있음 을 알 수가 있었다(table 1).

\section{1. 파노라마와 Digital Vernier Caliper의 비교}

파노라마와 Digital Vernier Caliper에서 측정된 길이 를 비교했을 때, 가장 큰 오차는 $1.6 \mathrm{~mm}$ 로 나타났으며, 가장 작은 오차는 $0.7 \mathrm{~mm}$ 로 나타났다. 두 방법을 비교 했을 때 크게는 $110.7 \%$, 작게는 $103.9 \%$ 로 평균적으로 파노라마가 $7.3 \%$ 로 확대됨을 알 수 있었다(table 2).

\section{2. $\mathrm{CBCT}$ 와 Digital Vernier Caliper의 비교}

$\mathrm{CBCT}$ 와 Digital Vernier Caliper에서 측정된 길이를 비교했을 때, 가장 큰 오차는 $0.3 \mathrm{~mm}$ 로 나타났으며, 가 장 작은 오차는 $0.1 \mathrm{~mm}$ 로 나타났다. 두 방법을 비교 했 을 때 크게는 $97.7 \%$, 작게는 $99.4 \%$ 로 평균적으로 $\mathrm{CBCT}$ 가 $-1.3 \%$ 로 축소됨을 알 수 있었다(table 3 ).

\section{3. 측정 방법에 따른 왜곡률 비교}

$\mathrm{CBCT}$ 와 Digital Vernier Caliper에서 측정된 사랑니의 길이는 오차범위 $1.3 \%$ 로 나타났고, 파노라마와 Digital Vernier Caliper에서 측정된 사랑니의 길이는 오차범위 
$7.3 \%$ 를 나타냄으로써 $\mathrm{CBCT}$ 가 파노라마보다 약 $6 \%$ 정 확한 영상을 나타냄을 알 수 있었다(Fig 4).

table 1. Wisdom tooth length of each methods

\begin{tabular}{cccc}
\hline Patient & panorama & CBCT & $\begin{array}{c}\text { Digital } \\
\text { Vernier } \\
\text { Cal iper }\end{array}$ \\
\hline \hline A & 15.2 & 14.1 & 14.2 \\
B & 18.5 & 17.5 & 17.8 \\
C & 16.8 & 15.8 & 15.9 \\
D & 16.6 & 14.9 & 15 \\
E & 14 & 12.6 & 12.9 \\
F & 17.1 & 15.7 & 16 \\
G & 18.6 & 17.5 & 17.7 \\
H & 16.9 & 15.7 & 15.8 \\
I & 14.1 & 12.8 & 13 \\
J & 16.4 & 14.8 & 15 \\
\hline & & & - 단위: $\mathrm{mm}$
\end{tabular}

table 2. Evaluate of panorama and Digital Vernier Caliper

\begin{tabular}{ccccc}
\hline Patient & panorama & $\begin{array}{c}\text { Digital } \\
\text { Vernier } \\
\text { Caliper }\end{array}$ & error & $\begin{array}{c}\text { percenta } \\
\text { ge(\%) }\end{array}$ \\
\hline \hline A & 15.2 & 14.2 & 1.0 & 107.0 \\
B & 18.5 & 17.8 & 0.7 & 103.9 \\
C & 16.8 & 15.9 & 0.9 & 105.7 \\
D & 16.6 & 15 & 1.6 & 110.7 \\
E & 14 & 12.9 & 1.1 & 108.5 \\
F & 17.1 & 16 & 1.1 & 106.9 \\
G & 18.6 & 17.7 & 0.9 & 105.1 \\
H & 16.9 & 15.8 & 1.1 & 107.0 \\
I & 14.1 & 13 & 1.1 & 108.5 \\
J & 16.4 & 15 & 1.4 & 109.3 \\
\hline
\end{tabular}

table 3. Evaluate of CBCT and Digital Vernier Caliper

\begin{tabular}{ccccc}
\hline Patient & CBCT & $\begin{array}{c}\text { Digital } \\
\text { Vernier } \\
\text { Caliper }\end{array}$ & error & $\begin{array}{c}\text { percenta } \\
\text { ge(\%) }\end{array}$ \\
\hline \hline A & 14.1 & 14.2 & 0.1 & 99.3 \\
B & 17.5 & 17.8 & 0.3 & 98.3 \\
C & 15.8 & 15.9 & 0.1 & 99.4 \\
D & 14.9 & 15 & 0.1 & 99.3 \\
E & 12.6 & 12.9 & 0.3 & 97.7 \\
F & 15.7 & 16 & 0.3 & 98.1 \\
G & 17.5 & 17.7 & 0.2 & 98.9 \\
H & 15.7 & 15.8 & 0.1 & 99.4 \\
I & 12.8 & 13 & 0.2 & 98.5 \\
J & 14.8 & 15 & 0.2 & 98.7 \\
\hline
\end{tabular}

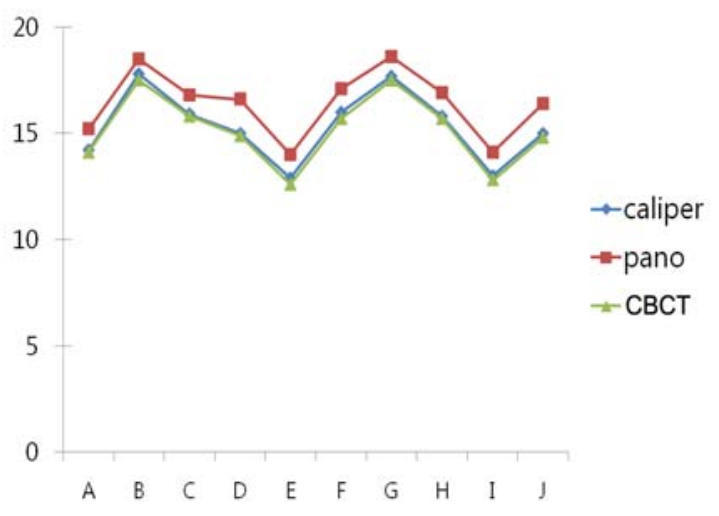

Fig 4. Comparison of each methods

\section{IV. 고 찰}

파노라마 촬영은 경제적이고 전반적인 해부학적 구 조를 시각화하고 많은 정보를 제공하기 때문에 임상 에서 가장 많이 활용되는 검사이지만 해상도가 낮고 불규칙한 확대를 보이며 상의 왜곡이 있으며 판독하 는데 있어 해부학적 구조물을 명확하게 구별하기가 어려우며 인접 구조물이 서로 겹치는 문제가 있다. 또 한 횡단면에 대한 정보를 알 수 없기 때문에 해부학적 구조물을 평가하는데 적절하지 않다 ${ }^{[11,12]}$.

치과에서 최근 적용되고 있는 새로운 영상화 기법 인 $\mathrm{CBCT}$ 는 고해상도의 영상과 위치 정보를 제공한다. 그리고 기존 CT보다 상대적으로 낮은 선량이며, 수술 전 진단과 치료 전 계획의 수립이 가능하고, 3 차원적 
"Journal of the Korean Society of Radiology, Volume 7, Number 2"

영상진단을 할 수 있어 치과 병, 의원에 급속도로 보 급되고 있다. 지금까지는 파노라마 영상과 해부학을 통한 연구가 주를 이루었으나 근래에는 $\mathrm{CBCT}$ 가 보급 되면서 이를 통한 3 차원적인 평가가 이루어지고 있다 [13]

본 연구에서는 실제 발치된 치아의 길이를 측정하 고 파노라마와 $\mathrm{CBCT}$ 로 측정된 사랑니 길이와 비교하 여 치아의 왜곡을 분석함으로써 파노라마와 $\mathrm{CBCT}$ 의 정확도를 분석하고, 치과 치료시 해부학적으로 유용한 정보를 얻고자 한다.

본 연구에서 파노라마와 Digital Vernier Caliper에서 측정된 길이를 비교했을 때, 가장 큰 오차는 $1.6 \mathrm{~mm}$ 로 나타났으며, 가장 작은 오차는 $0.7 \mathrm{~mm}$ 로 나타났다. 두 방법을 비교 했을 때 크게는 $110.7 \%$, 작게는 $103.9 \%$ 로 평균적으로 파노라마가 평균 $7.3 \%$ 로 확대됨을 알 수 있었다. $\mathrm{CBCT}$ 와 Digital Vernier Caliper에서 측정된 길 이를 비교했을 때, 가장 큰 오차는 $0.3 \mathrm{~mm}$ 로 나타났으 며, 가장 작은 오차는 $0.1 \mathrm{~mm}$ 로 나타났다. 두 방법을 비교 했을 때 크게는 $97.7 \%$, 작게는 $99.4 \%$ 로 평균적으 로 $\mathrm{CBCT}$ 가 $-1.3 \%$ 로 축소됨을 알 수 있었다. $\mathrm{CBCT}$ 와 Digital Vernier Caliper에서 측정된 사랑니의 길이는 오 차범위 $1.3 \%$ 로 나타났고, 파노라마와 Digital Vernier Caliper에서 측정된 사랑니의 길이는 오차범위 $7.3 \%$ 를 나타냄으로써 CBCT가 파노라마보다 약 $6 \%$ 정확한 영 상을 나타냄을 알 수 있었다.

그러나 본 연구의 결과와 같이 $\mathrm{CBCT}$ 가 파노라마보 다 정확하다고해서 $\mathrm{CBCT}$ 만 검사할 수 없는 실정이다. 그 이유는 첫째, $\mathrm{CBCT}$ 가 파노라마에 비해 검사비용이 $20 \sim 30$ 배 정도 비싸다는 점이다. 둘째, $\mathrm{CBCT}$ 의 피폭선 량 역시 파노라마에 비해 5 11배 이상의 차이를 보이 고 있다. 따라서 치과 방사선 검사 시 촬영부위와 질 환에 따른 적절한 방법을 찾아야 할 것으로 사료된다 [14]

\section{$\mathrm{V}$. 결 론}

본 논문에서는 실제 발치된 치아의 길이를 측정하 고 파노라마와 $\mathrm{CBCT}$ 로 측정된 사랑니 길이와 비교하 여 치아의 왜곡을 분석함으로써 파노라마와 $\mathrm{CBCT}$ 의 정확도를 분석하고, 치과 치료시 해부학적으로 유용한
정보를 얻고자 하였다.

실험 결과 실제 치아와 비교 했을 때 CBCT가 $1.3 \%$, 파노라마가 $7.3 \%$ 의 오차범위를 보였다. $\mathrm{CBCT}$ 가 파노 라마보다 정확한 영상을 나타냄을 확인할 수 있었지 만 $\mathrm{CBCT}$ 는 파노라마보다 검사비용이 비싸고 피폭선 량도 많은 단점이 있다.

현재 많은 $\mathrm{CBCT}$ 프로그램과 재구성의 방법들이 개 발되고 있으므로, 교정이나 외과적 발치 검사 시 영상 의 확대나 왜곡을 줄일 수 있는 적절한 진단 방법을 찾아야 할 것으로 사료된다.

\section{참고문헌}

[1] 임청환, 김승철, 정홍량 외, “치과 방사선 검사 시 노출 위험성에 따른 피폭선량 방어연구”, 한국방사선학회지, Vol. 5, No. 5, pp238-239, 2011.

[2] 정천수, 모은희, 이기흔 외, “ $\mathrm{CBCT}$ 영상에서 구치부의 하악관 형태에 다른 재구성 방법 연구”, 한국방사선학회지, Vol. 5, No. 6, pp.370-374, 2011.

[3] Stramotas S, Geenty JP, Petocz P, Darendeliler MA. Accuracy of linear a nd angula $\mathrm{r}$ measurements on panoramic radiographs taken at various pos itions in vitro. Eur J Orthod Vol. 24, pp.43-52, 2002.

[4] Choi YS, Hwang HE, Lss SR, "Clinical application of cone beam computed tomography in dental implant", J Korean Dent Assoc, Vol. 44, pp.172-179, 2006.

[5] Pinsky HM, Dydal S, Pinsky RW, Misch KA, Sarment DP, "Accuracy of three-dimensional measurements using cone-beam CT, Dentomaxillofac Radiol, Vol. 35, pp.410-416, 2006.

[6] Mah JK, Danforth RA, Bumann A, Hatcher D. Radiation absorbed in maxillofacial imaging with a new dental computed tomography device. Oral Surg Oral Med Oral Pathol Oral Radiol Endod, Vol. 96, pp. 508-13, 2003.

[7] Tsiklakis K, Donta C, Gavala S, Karayianni K, Kamenopoulou $\mathrm{V}$, Hourdakis CJ. Dose reduction in maxillofacial imaging using low dose Cone Beam CT. Eur J Radiol, Vol. 56, pp. 413-7, 2005.

[8] Halazonetis DJ. From 2-dimensional cephalograms to 3-dimensional computed tomography scans. Am J Orthod Dentofacial Orthop, Vol. 127, pp. 627-37, 2005.

[9] Huang J, Bumann A, Mah J. Three-dimensional radiographic analysis in orthodontics. J Clin Orthod, Vol. 39, pp. 421-8, 2005. 
[10] 치위생과임상연구회, “치과임상 기초”, 고문사, pp.216, 2002.

[11] Lee JH,Han WJ,ChoiYH,Kim EK. "Measurementofmaxillary sinus volume and available alveolar bone height using computed tomography“, KoreanJOralMaxillofacRadiol, Vol. 33, pp.35-41, 2003.

[12] 전혜진, "CBCT를 이용한 상악동 중격의 진단 및 파노라마 방사선 사진의 정확도”, 이화여자대학교 임상치의학대학원, 석사학위논문, pp.2-3, 2011.

[13] Pinsky HM, Dydal S, Pinsky RW, Misch KA, Sarment DP, "Accuracy of three-dimensional measurements using cone-beam CT, Dentomaxillofac Radiol, Vol. 35, pp.410-416, 2006.

[14] 최성일, “치과용 디지털 파노라마 영상시스템의 화질개선 방안에 관한 연구”, 연세대학교 대학원, 석사학위논문, pp.23-44. 2007. 